\title{
Precipitation and Distribution Behavior of In Situ-Formed TiB Whiskers in Ti64 Composites Fabricated by Selective Laser Melting
}

\author{
Junko Umeda ${ }^{1, *}$, Lei Jia ${ }^{2}$, Biao Chen ${ }^{3}$, Ke Chen ${ }^{4}$, Shufeng Li ${ }^{2}$, Kazuki Shitara ${ }^{1}$ and Katsuyoshi Kondoh ${ }^{1}$ \\ 1 Joining and Welding Research Institute, Osaka University, Ibaraki 5670047, Japan; \\ shitara@jwri.osaka-u.ac.jp (K.S.); kondoh@jwri.osaka-u.ac.jp (K.K.) \\ 2 School of Materials Science and Engineering, Xi'an University of Technology, Xi'an 710048, China; \\ jialei@xaut.edu.cn (L.J.); shufengli@xaut.edu.cn (S.L.) \\ 3 State Key Laboratory of Solidification Processing, Northwestern Polytechnical University, \\ Xi'an 710072, China; chen@nwpu.edu.cn \\ 4 Shanghai Key Laboratory of Materials Laser Processing and Modification, Shanghai Jiao Tong University, \\ No. 800, Dong Chuan Road, Shanghai 200240, China; chenke83@sjtu.edu.cn \\ * Correspondence: umedaj@jwri.osaka-u.ac.jp
}

Citation: Umeda, J.; Jia, L.; Chen, B.; Chen, K.; Li, S.; Shitara, K.; Kondoh, K. Precipitation and Distribution Behavior of In Situ-Formed TiB Whiskers in Ti64 Composites Fabricated by Selective Laser Melting Crystals 2021, 11, 374. https:// doi.org/10.3390/cryst11040374

Academic Editors:

Katsuyoshi Kondoh,

Abdollah Bahador,

Ridvan Yamanoglu and Sergio Brutti

Received: 9 March 2021

Accepted: 31 March 2021

Published: 3 April 2021

Publisher's Note: MDPI stays neutral with regard to jurisdictional claims in published maps and institutional affiliations.

Copyright: () 2021 by the authors. Licensee MDPI, Basel, Switzerland. This article is an open access article distributed under the terms and conditions of the Creative Commons Attribution (CC BY) license (https:// creativecommons.org/licenses/by/ $4.0 /)$.
Abstract: The precipitation and distribution behaviors of in situ-formed titanium boride whiskers (TiB) in TiBw-reinforced Ti-6\%Al-4\%V (Ti64) composites fabricated from an elemental mixture of Ti64 alloy powder and $\mathrm{TiB}_{2}$ particles by selective laser melting were investigated. The primary precipitation of $\mathrm{TiB}$ whiskers strongly depends on B content. For a B content of less than 2 mass $\%$, when the liquid $\rightarrow \beta$-phase transformation occurred and B atoms were discharged, the B-enriched area formed around the $\beta$-phase resulted in the generation of TiB whiskers and their agglomeration at the prior $\beta$-grain boundaries. When the B content was over 2 mass $\%$, TiB whiskers directly precipitated from the liquid phase and moved to the molten pool boundary via Marangoni convection. As a result, the TiB whiskers were located along the boundary. Furthermore, B-enrichment caused a decrease in the liquidus temperature and thus obstructed $\beta$-grain coarsening, and as a result, fine equiaxed $\alpha^{\prime}$-grains formed during the phase transformation.

Keywords: TiB whiskers; Ti64 composites; selective laser melting

\section{Introduction}

The selection of reinforcements for metal matrix composites is crucial to significantly improve the chemical and mechanical properties of monolithic metal materials. Titanium boride whisker $(\mathrm{TiBw})$ reinforcements are often employed for titanium because of their high strength and modulus, similar density and coefficient of thermal expansion, and strong interfacial bonding with the Ti matrix [1-4]. In particular, thermally stable TiBw can easily form via an in situ reaction between $\mathrm{Ti}$ powder and boride or $\mathrm{TiB}_{2}$ particles $[5,6]$. The in situ formation mechanism of TiBw was clarified in a previous study [7], and others have shown that strong orientation of the whiskers enhances the mechanical strength of $\mathrm{Ti}$ composites [8-10].

Recently, selective laser melting (SLM), an additive manufacturing technology, has been employed to fabricate Ti alloys and composites because the rapid solidification and cooling afford Ti grain refinement, supersaturated solutions of the alloying elements, and fine precipitates [11-13]. TiBw-reinforced Ti- $6 \% \mathrm{Al}-4 \% \mathrm{~V}$ (Ti64) alloy composites fabricated by SLM show a large improvement in matrix microhardness due to grain refinement and hard TiBw dispersoids, resulting in a decrease in both the wear loss and friction coefficient as determined by tribological evaluation. In addition, a unique Ti composite powder coated with $\mathrm{TiB}_{2}$ particles has been used to fabricate SLM Ti-TiBw composites with networkstructured whiskers formed in situ at primary powder boundaries, resulting in an extreme 
improvement in tensile strength [14]. Furthermore, a previous study discussed the effect of heat treatment on the formation of equiaxed $\alpha$-Ti grains in TiBw-reinforced Ti composites fabricated by SLM [15]. The in situ-formed TiBw reinforcements not only strengthened the material but also acted as additional nucleation sites for $\alpha-\mathrm{Ti}$, thus promoting the formation of equiaxed microstructures.

The microstructural analyses in these previous studies indicated morphological changes occurring in TiBw (aspect ratio), but there have been no reports on the TiBw precipitation or distribution mechanisms during the liquid $\rightarrow \beta$ and $\beta \rightarrow \alpha$ phase transformations. The objective of this study was to clarify the distribution mechanism of TiB whiskers formed in situ in SLM Ti64 composites fabricated from an elemental mixture of Ti64 alloy powder and $\mathrm{TiB}_{2}$ particles. Of particular interest was the effect of the boron (B) content, which strongly influences the TiBw precipitation behavior during the phase transformations, on the morphologies of the prior $\beta$-phases and acicular $\alpha^{\prime}$-grains.

\section{Materials and Methods}

\subsection{Elemental Mixture of Ti64 Alloy Powder and $\mathrm{TiB}_{2}$ Particles}

Gas-atomized Ti64 pre-alloy powder (Osaka Titanium Technologies, Osaka, Japan) with a spherical shape and $\mathrm{TiB}_{2}$ particles (KOJUNDO Chemical Laboratory) was employed as the starting raw material, as shown in Figure 1. The mean particle sizes were 23.6 and $3.2 \mu \mathrm{m}$, respectively. The maximum and minimum sizes of Ti64 and $\mathrm{TiB}_{2}$ were $31.5 \mu \mathrm{m}$ and $6.6 \mu \mathrm{m}$, and $4.4 \mu \mathrm{m}$ and $0.85 \mu \mathrm{m}$. Table 1 shows the chemical composition of the Ti64 alloy powder compared to ASTM B348 Grade 5 specifications. All elements satisfied the standard ASTM Grade 5 requirements. Ti64 and $x$ mass $\% \mathrm{TiB}_{2}$ pre-mixed powders $(x=0$, $0.25,0.5,1,5$, and 10 ) were prepared by a table ball-milling process with a rotating speed of $90 \mathrm{rpm}$ and a milling time of $12 \mathrm{~h}$. The weight ratio of $10 \mathrm{~mm}$ zirconia $\left(\mathrm{ZrO}_{2}\right)$ media balls to the pre-mixed powder was 0.2 (powder: media ball $=5: 1$ ). Figure 1 c shows that the fine $\mathrm{TiB}_{2}$ particles were mechanically embedded and uniformly dispersed in the Ti64 alloy powder surface with a spherical shape after $12 \mathrm{~h}$ of milling the pre-mixed $\mathrm{Ti} 64-10 \% \mathrm{TiB}_{2}$ powder. This indicated that both the raw Ti64 alloy powder and the elemental-mixture powder had good flowability.
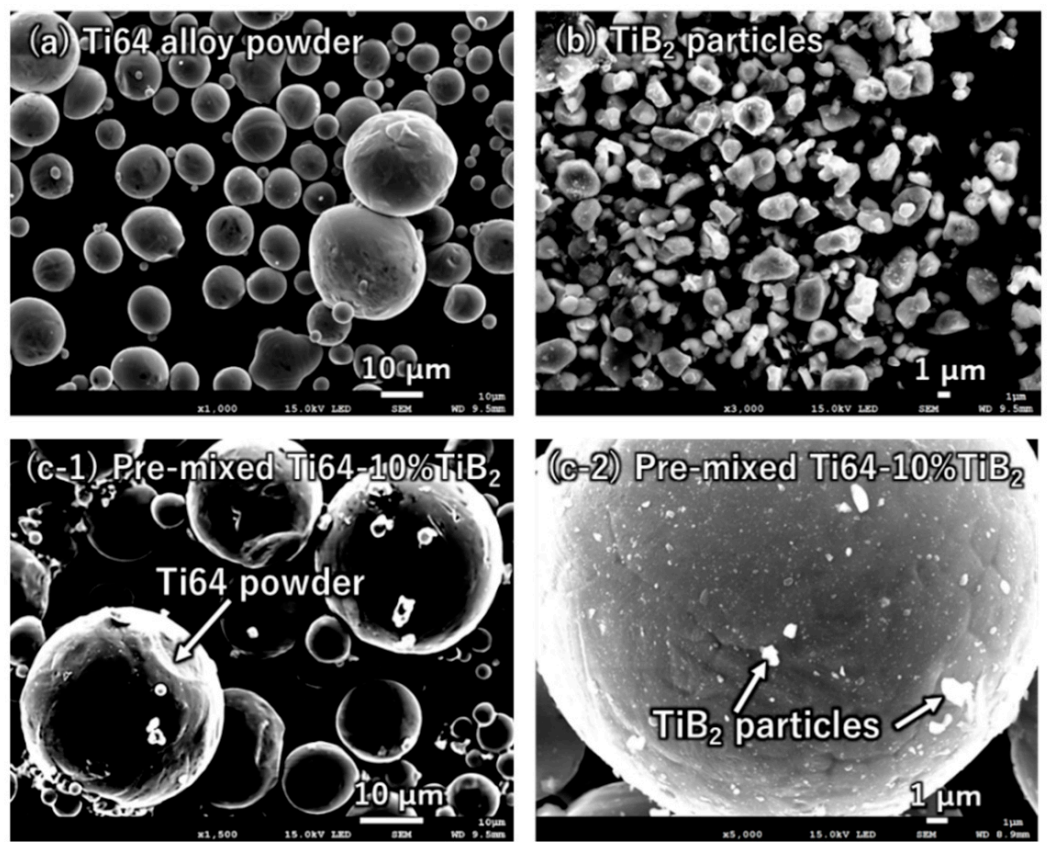

Figure 1. SEM images of the (a) TiBw-reinforced Ti-6\%Al-4\%V (Ti64) alloy powder, (b) $\mathrm{TiB}_{2}$ particles, and (c) Ti64-10\%TiB 2 elemental mixture used in this study (c-1: 10 um; c-2: 1 um). 
Table 1. Chemical composition of Ti-6Al-4V alloy powder used as a raw material in this study compared to ASTM B348 Grade 5 standard values.

\begin{tabular}{cccccccc}
\hline & \multicolumn{7}{c}{ Elements (mass\%) } \\
\cline { 2 - 8 } & Fe & Al & H & N & C & O & V \\
\hline Ti-6Al-4V Powder & 0.20 & 6.21 & $<0.01$ & 0.01 & $<0.01$ & 0.15 & 4.33 \\
\hline ASTM B348 Grade 5 & $<0.4$ & $5.50 \sim 6.75$ & $<0.015$ & $<0.05$ & $<0.08$ & $<0.25$ & $3.5 \sim 4.5$ \\
\hline
\end{tabular}

\subsection{SLM Process Conditions}

An ytterbium $(\mathrm{Yb})$ fiber laser-installed SLM system (TruPrint1000) with a maximum power of $200 \mathrm{~W}$ was used to fabricate cuboid Ti64 composites $(10 \mathrm{~mm} \times 40 \mathrm{~mm} \times 8 \mathrm{~mm})$. The layer thickness $(t)$, laser spot diameter, and hatch distance $(h)$ were 20, 30, and $110 \mu \mathrm{m}$, respectively. The scanning strategy was a chessboard pattern with a size of $4 \mathrm{~mm} \times 4 \mathrm{~mm}$, which was rotated by $90^{\circ}$ layer to layer. The optimized energy density $(E)$ calculated by the below equation is important for preparing samples with a high relative density and no pores or defects [16].

$$
E=P / \text { vht }(P: \text { laser powder }[\mathrm{W}], v: \text { scanning speed }[\mathrm{mm} / \mathrm{s}])
$$

The preliminary experimental results for parameter optimization using the Ti64 prealloy powder are summarized in Table 2, where the laser power and scanning speed were changed. Surface morphology observations and measurements of the relative density and oxygen $(\mathrm{O})$ and nitrogen $(\mathrm{N})$ contents of the SLM samples were carried out. A lower energy density can lead to unmelted powder and pores in the bulk sample. On the other hand, a higher energy density can result in spattering and accelerate the reaction of the Ti powder with $\mathrm{O}_{2}$ and $\mathrm{N}_{2}$ in the chamber during SLM. An increase in the $\mathrm{O}$ or $\mathrm{N}$ content decreases the ductility of Ti materials owing to their solid solution in the $\alpha$-Ti phase. Therefore, the optimum energy density in this study was determined to be $136 \mathrm{~J} / \mathrm{mm}^{3}$ as this enables the highest density (99.3\%) and lowest contents of $\mathrm{O}$ and $\mathrm{N}$ elements in the samples.

Table 2. Selective laser melting (SLM) parameters for fabricating the Ti64 alloys and summary of the measured relative density, oxygen content, and nitrogen content of the SLM Ti64 alloys.

\begin{tabular}{|c|c|c|c|c|c|c|c|c|c|c|c|c|}
\hline $\begin{array}{l}\text { Energy Density, } E \\
\left(\mathrm{~J} / \mathrm{mm}^{3}\right)\end{array}$ & 45.4 & 90.9 & 136 & 227 & 455 & 497 & 519 & 568 & 606 & 727 & 663 & 795 \\
\hline Laser power, $P(\mathrm{~W})$ & 160 & 160 & 160 & 160 & 160 & 175 & 160 & 175 & 160 & 160 & 175 & 175 \\
\hline Scan speed, $v(\mathrm{~mm} / \mathrm{s})$ & 1600 & 800 & 535 & 320 & 160 & 160 & 140 & 140 & 120 & 100 & 120 & 100 \\
\hline Hatch distance, $h(\mathrm{~mm})$ & 0.11 & 0.11 & 0.11 & 0.11 & 0.11 & 0.11 & 0.11 & 0.11 & 0.11 & 0.11 & 0.11 & 0.11 \\
\hline Layer thickness, $t$ (mm) & 0.02 & 0.02 & 0.02 & 0.02 & 0.02 & 0.02 & 0.02 & 0.02 & 0.02 & 0.02 & 0.02 & 0.02 \\
\hline Relative density (\%) & 98.5 & 99.2 & 99.3 & 99.0 & 99.1 & 99.1 & 99.1 & 99.3 & 98.9 & 98.2 & 98.8 & 98.3 \\
\hline Oxygen content ${ }^{*}(\operatorname{mass} \%)$ & 0.21 & 0.21 & 0.21 & 0.22 & 0.25 & 0.25 & 0.27 & 0.26 & 0.28 & 0.31 & 0.31 & 0.40 \\
\hline Nitrogen content* (mass \%) & 0.02 & 0.02 & 0.02 & 0.03 & 0.04 & 0.06 & 0.06 & 0.05 & 0.06 & 0.06 & 0.08 & 0.10 \\
\hline
\end{tabular}

\subsection{Microstructural Analysis}

The microstructures of the SLM Ti64-TiBw composites were observed using an optical microscope and a field-emission scanning electron microscope (SEM, JSM-7100F, JEOL). The orientation and texture were investigated using electron backscatter diffraction (EBSD) with a high-speed and high-sensitivity CCD camera (DigiView IV Detector, EDSA-TSL). The crystalline structure and Ti grain size were analyzed from the EBSD patterns using the TSL OIM collection and analysis software. Each specimen for EBSD analysis was electrochemically polished with a polishing solution consisting of $95 \mathrm{vol} \%$ acetic acid $\left(\mathrm{CH}_{3} \mathrm{COOH}\right)$ and $5 \mathrm{vol} \%$ perchloric acid $\left(60 \% \mathrm{HClO}_{4}\right)$. Electrolytic polishing was performed using a magnetic stirrer for $90-180 \mathrm{~s}$ at room temperature. After polishing, the samples were rinsed immediately with ethanol. X-ray diffraction analysis (Shimadzu XRD-6100 
diffractometer) was used to identify the phases using $\mathrm{Cu} \mathrm{K} \alpha$ radiation at $40 \mathrm{kV}$ and $30 \mathrm{~mA}$ (scan speed of $2^{\circ} / \mathrm{min}$ and scan step size of $0.02^{\circ}$ in the $2 \theta$ range of $30^{\circ}-80^{\circ}$ ). In discussion of TiB formation mechanism during cooling in SLM process, the calculated partial pseudo-binary phase diagram of (Ti-6\%Al-4\%V)- $\mathrm{x} \% \mathrm{~B}(\mathrm{x}=0-5$ mass $\%)$, which was prepared by Pandat CALPHAD software, was employed.

\subsection{Laser Irradiation Experiments}

A single laser irradiation procedure was applied to green compacts of the pre-mixed Ti64 powder with $\mathrm{TiB}_{2}$ particles $(1 \%, 5 \%$, and $10 \%)$ to clarify the microstructural formation in the molten pool. The pre-mixed powder was heated at $673 \mathrm{~K}$ for $300 \mathrm{~s}$ in an argon gas atmosphere and immediately consolidated in an SKD61 die, which was also heated at $673 \mathrm{~K}$. A compaction pressure of $600 \mathrm{MPa}$ was applied to fabricate a green compact with a high relative density of more than $99 \%$. The in situ formation and distribution of $\mathrm{TiB}$ whiskers were investigated by microstructural observation of the molten pool after laser irradiation.

\section{Results and Discussion}

\subsection{Microstructural Analysis of SLM Ti64 Composites with Different TiBw Contents}

As mentioned above, previous studies have demonstrated that TiBw forms in Ti64 alloy composites fabricated by SLM from an elemental mixture of Ti64 alloy powder and $\mathrm{TiB}_{2}$ particles. $\mathrm{XRD}$ analysis was applied to analyze the raw materials, elemental mixtures, and materials fabricated by SLM. Figure 2 a shows that no $\mathrm{TiB}_{2}$ diffraction peak was present in the XRD profiles of the SLM Ti64-1\%, $5 \%$, or $10 \% \mathrm{TiB}_{2}$ composites, whereas the pre-mixed Ti64- $1 \% \mathrm{TiB}_{2}$ powder showed a $\mathrm{TiB}_{2}$ diffraction peak at $2 \theta=44.44^{\circ}$. The $\mathrm{XRD}$ narrow-scanned profile of the SLM Ti64- $1 \% \mathrm{TiB}_{2}$ composite in Figure $2 \mathrm{~b}$ also shows a TiB diffraction peak at $2 \theta=42.26^{\circ}$ but no $\mathrm{TiB}_{2}$ peak. It was concluded that the additional $\mathrm{TiB}_{2}$ raw particles completely reacted with the Ti64 powder, resulting in the in situ formation of $\mathrm{TiB}$ compounds during the SLM process.
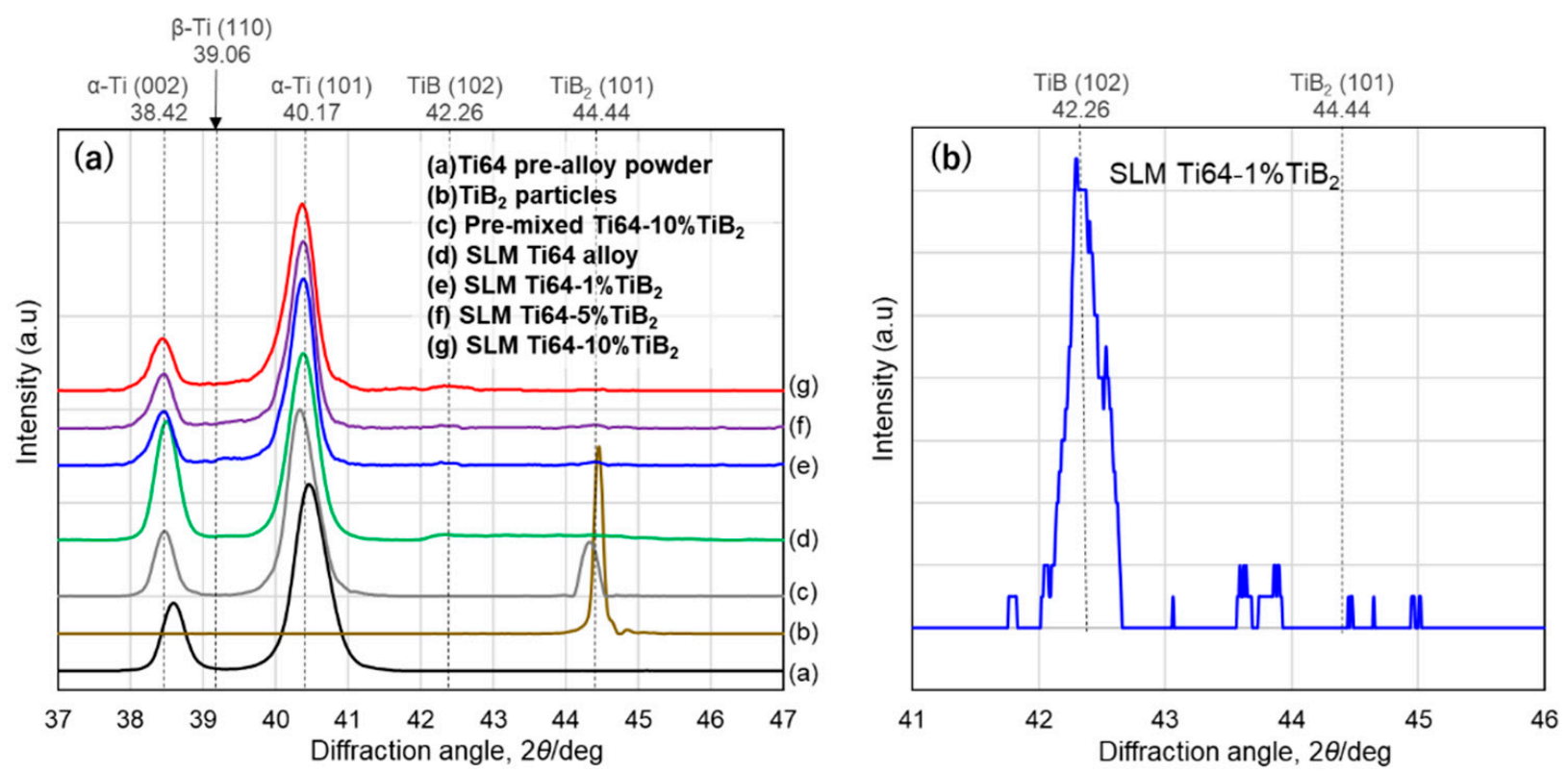

Figure 2. (a) XRD profiles of the Ti64 alloy powder, $\mathrm{TiB}_{2}$ particles, pre-mixed Ti64-10\%TiB 2 powder, SLM Ti64 alloy, SLM Ti64-1\% $\mathrm{TiB}_{2}$ alloy, SLM Ti64-5\% $\mathrm{TiB}_{2}$ alloy, and SLM Ti64-10\% $\mathrm{TiB}_{2}$ alloy. (b) Narrow-scanned XRD profile of the SLM Ti64-1\% $\mathrm{TiB}_{2}$ composite. 
According to the calculated partial pseudo-binary phase diagram of (Ti-6Al-4V)- $x \mathrm{~B}$ $(x=0-5$ mass $\%)$ shown in Figure 3, the TiBw precipitation behavior depends on the boron content as follows:

$\mathrm{B}<2$ mass\% (Group I) (1) Liquid (L) phase $\rightarrow$ (2) $\mathrm{L}+\beta \rightarrow(3) \mathrm{L}+\beta+\underline{\mathrm{TiB}} \rightarrow$ (4) $\beta+\mathrm{TiB}$

$\mathrm{B}>2$ mass $\%$ (Group II) (1) L phase $\rightarrow$ (2) $\mathrm{L}+\underline{\mathrm{TiB}} \rightarrow$ (3) $\mathrm{L}+\beta+\mathrm{TiB} \rightarrow(4) \beta+\mathrm{TiB}$

Therefore, this study aimed to clarify the TiBw precipitation and distribution behaviors of SLM Ti64 alloy composites with different $\mathrm{TiB}_{2}$ contents.
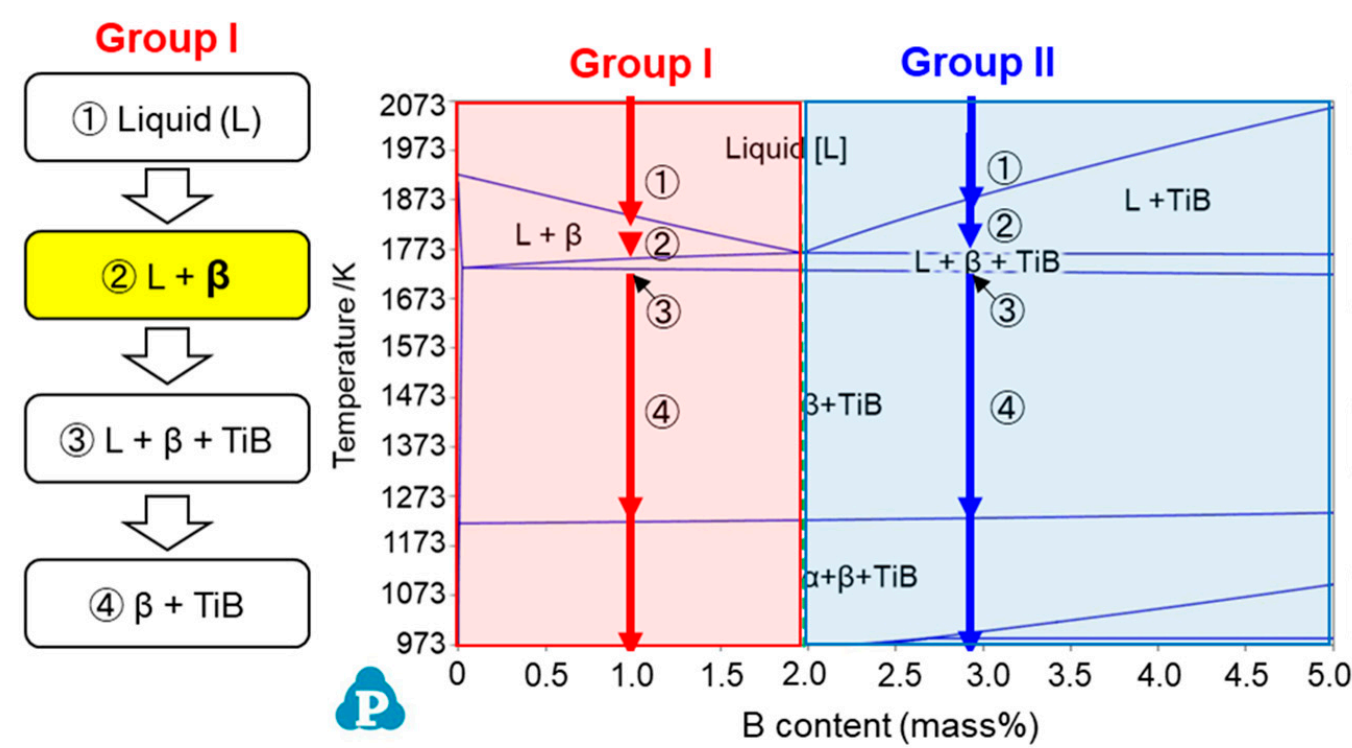

Group II

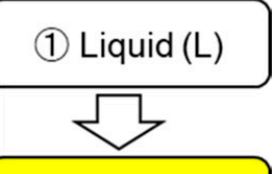

(2) $L+T i B$

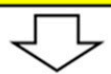

(3) $L+\beta+T i B$

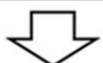

(4) $\beta+\mathrm{TiB}$

Figure 3. Calculated partial pseudo-binary phase diagram of (Ti-6Al-4V)- $x \mathrm{~B}(x=0-5$ mass $\%)$.

SEM-EDS analysis was applied to determine the microstructural differences in the SLM Ti64 composites with $1 \% \mathrm{TiB}_{2}$ (0.31 mass \% B), 5\% $\mathrm{TiB}_{2}\left(1.53\right.$ mass $\% \mathrm{~B}$ ), and $10 \% \mathrm{TiB}_{2}$ (3.06 mass\% B). As shown in the compositional images (COMPO) in Figure 4, there was clear contact between the molten pool boundaries in all samples. The Ti64-1\% and 5\% $\mathrm{TiB}_{2}$ samples had U-shaped contacts, and their shades were not clear. With $10 \% \mathrm{TiB}_{2}$ particles, a $\mathrm{V}$-shaped contact with a maximum depth of approximately $100 \mu \mathrm{m}$ was formed, and its shade became much clearer. EDS analysis of the $\mathrm{Ti} 64-10 \% \mathrm{TiB}_{2}$ sample (Figure $4 \mathrm{c}$ ) showed needle-like compounds near the molten pool boundaries with a length of $1 \mu \mathrm{m}$ and higher B contents (20.6-33.3 at.\%) than the matrix.

A detailed investigation by SEM-EDS of the TiBw distributions in the Ti64 composites with $1 \%$ and $5 \% \mathrm{TiB}_{2}$ after chemical etching was carried out. First, according to the SEM images of the monolithic Ti64 alloy and 1\% $\mathrm{TiB}_{2}$-added Ti64 composite in Figure 5, both samples clearly contained acicular martensite $\left(\alpha^{\prime}\right)$ phases tilted $45^{\circ}$ with respect to the $z$-direction (building direction). The length of the $\mathrm{Ti}^{2} 4-1 \% \mathrm{TiB}_{2}$ composite was less than $50 \mu \mathrm{m}$ : less than the length of the monolithic sample $(>100 \mu \mathrm{m})$. In addition, the image in Figure 5(b-1) clearly shows in situ-formed TiB whiskers with a length of approximately $1 \mu \mathrm{m}$ and width of $200 \mathrm{~nm}$, which uniformly existed along the building direction inside the prior $\beta$-grains. EDS analysis showed that these whiskers contained 2.8-10.8 at.\% B element. At the same time, agglomeration of acicular TiBw with 2.8-18.6 at.\% B content was also observed on the prior $\beta$-grain boundaries, as shown in Figure $5(\mathrm{~b}-2)$. The Ti64-5\% $\mathrm{TiB}_{2}$ sample (Figure 5c) showed much smaller equiaxed grains with a diameter of approximately $1 \mu \mathrm{m}$ and very small TiBw with B contents of 7.0-11.7 at.\% agglomerated at the prior $\beta$ grain boundaries. As shown in Figure 6, SEM-EDS analyses of the chemically etched $\mathrm{Ti} 64-10 \% \mathrm{TiB}_{2}$ sample under a higher magnification clearly revealed in situ-formed TiBw with lengths of 3-10 $\mu \mathrm{m}$ and B contents of 38.3-42.8 at.\% distributed along the molten pool boundaries with a V-shaped contact, as shown in Figure 4c. 


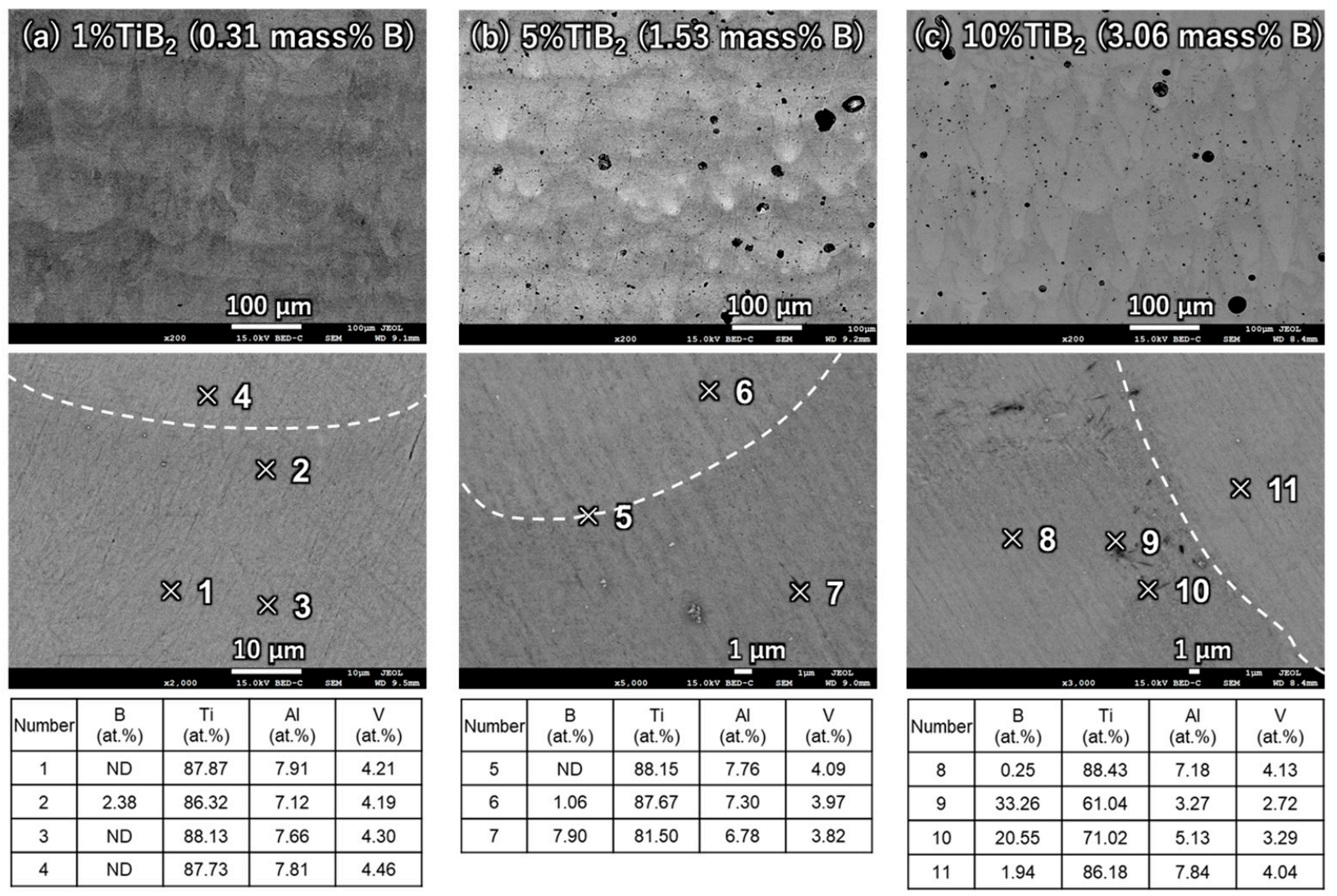

Figure 4. Compositional images (COMPO) and quantitative SEM-EDS analysis of SLM Ti64- (a) 1, (b) 5, and (c) 10 mass \% $\mathrm{TiB}_{2}$ alloy composites.
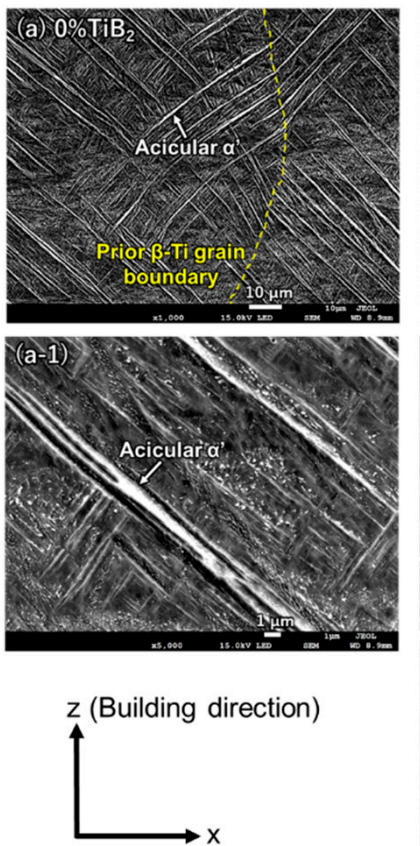
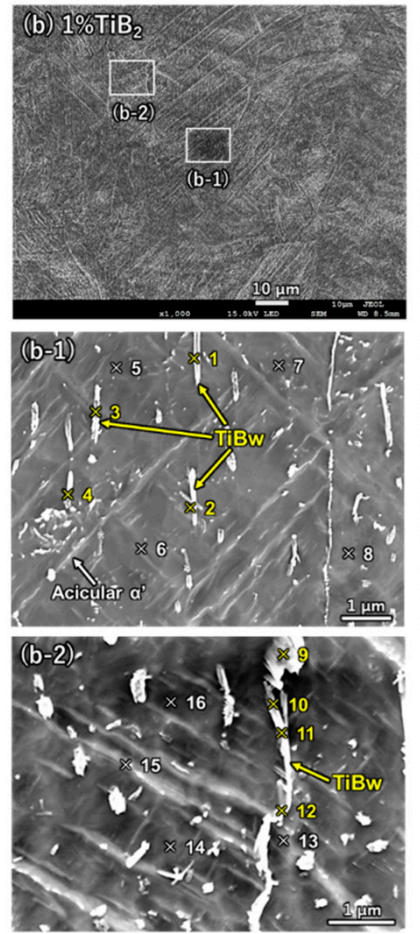

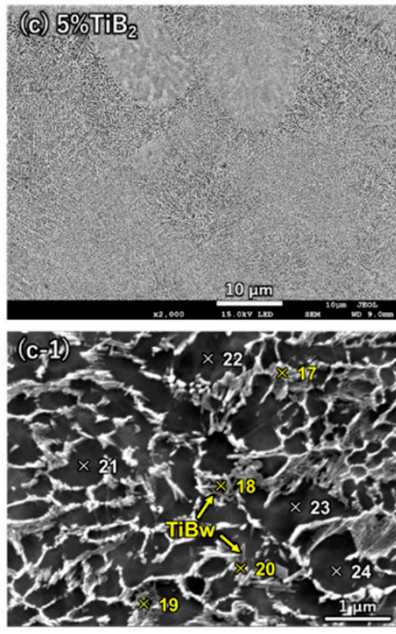

$\mathrm{TiB}$ whiskers

Ti matrix

\begin{tabular}{|c|c|c|c|c|}
\hline Number & $\begin{array}{c}\mathrm{B} \\
\text { (at.\%) }\end{array}$ & $\begin{array}{c}\mathrm{Ti} \\
\text { (at\%) }\end{array}$ & $\begin{array}{c}\mathrm{Al} \\
\text { (at\%) }\end{array}$ & $\begin{array}{c}\mathrm{V} \\
\text { (at\%) }\end{array}$ \\
\hline 1 & 2.77 & 85.46 & 7.45 & 4.32 \\
\hline 2 & 10.79 & 78.48 & 6.77 & 3.95 \\
\hline 3 & 7.56 & 81.12 & 7.16 & 4.15 \\
\hline 4 & 4.78 & 83.26 & 7.65 & 4.32 \\
\hline 5 & ND & 88.26 & 7.28 & 4.45 \\
\hline 6 & ND & 88.21 & 7.30 & 4.43 \\
\hline 7 & ND & 88.02 & 7.40 & 4.59 \\
\hline 8 & ND & 88.07 & 7.42 & 4.51 \\
\hline Number & $\begin{array}{c}\text { B } \\
\text { (at.\%) }\end{array}$ & $\begin{array}{c}\text { Ti } \\
\text { (at.\%) }\end{array}$ & $\begin{array}{c}\text { Al } \\
\text { (at.\%) }\end{array}$ & $\begin{array}{c}\mathrm{V} \\
\text { (at.\%) }\end{array}$ \\
\hline 9 & 18.59 & 71.99 & 5.67 & 3.67 \\
\hline 10 & 13.44 & 76.59 & 6.30 & 3.69 \\
\hline 11 & 12.56 & 77.37 & 6.33 & 3.74 \\
\hline 12 & 2.38 & 86.32 & 7.12 & 4.19 \\
\hline 13 & ND & 87.87 & 7.91 & 4.21 \\
\hline 14 & ND & 88.18 & 7.38 & 4.44 \\
\hline 15 & ND & 88.01 & 7.79 & 4.20 \\
\hline 16 & ND & 88.09 & 7.70 & 4.21 \\
\hline \hline Number & $\begin{array}{c}\mathrm{B} \\
\text { (at.\%) }\end{array}$ & $\begin{array}{c}\mathrm{Ti} \\
\text { (at.\%) }\end{array}$ & $\begin{array}{c}\text { Al } \\
\text { (at\%) }\end{array}$ & $\begin{array}{c}\mathrm{V} \\
\text { (at\%) }\end{array}$ \\
\hline 17 & 6.98 & 82.28 & 6.65 & 3.72 \\
\hline 18 & 10.25 & 79.03 & 6.88 & 3.83 \\
\hline 19 & 10.15 & 79.08 & 6.89 & 3.88 \\
\hline 20 & 11.69 & 77.94 & 6.65 & 3.72 \\
\hline 21 & ND & 88.47 & 7.37 & 4.16 \\
\hline 22 & ND & 88.43 & 7.28 & 4.29 \\
\hline 23 & ND & 88.26 & 7.59 & 4.15 \\
\hline 24 & ND & 88.37 & 7.56 & 4.07 \\
\hline
\end{tabular}

Figure 5. EDS analysis of SLM Ti64- (a) 1 and (b,c) 5 mass $\% \mathrm{TiB}_{2}$ alloys: $(-1)$ inside prior $\beta$-grains and (-2) on prior $\beta$-grain boundaries. 

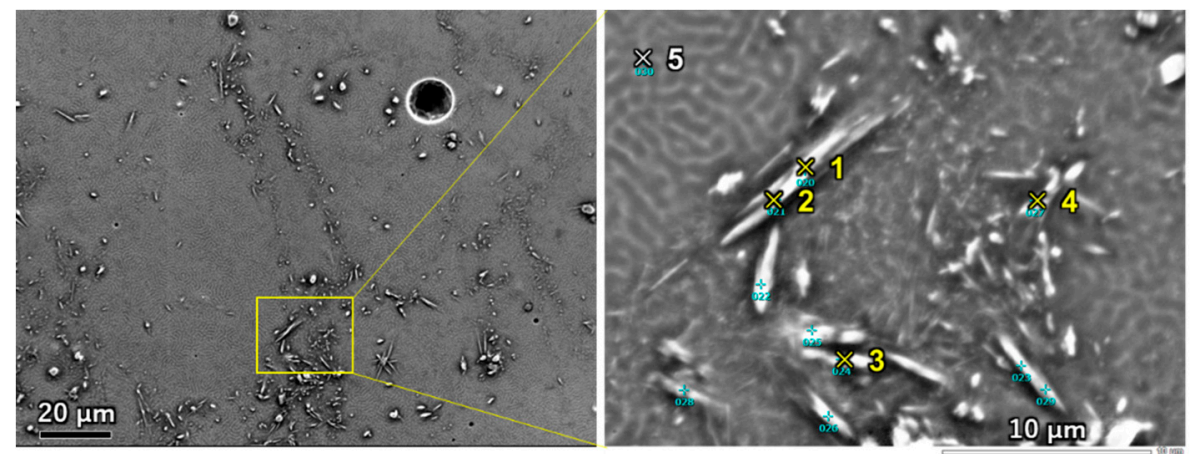

\begin{tabular}{|c|c|c|}
\hline No. & $\mathrm{B}($ at. \%) & $\mathrm{Ti}$ (at.\%) \\
\hline 1 & 42.79 & 51.34 \\
\hline 2 & 38.27 & 55.23 \\
\hline 3 & 38.31 & 53.25 \\
\hline 4 & 38.95 & 51.91 \\
\hline 5 & 6.51 & 82.89 \\
\hline
\end{tabular}

Figure 6. SEM-EDS observation of SLM Ti64-10 mass $\% \mathrm{TiB}_{2}$ composite TiBw distribution and quantitative analysis of TiBw.

To investigate the changes in the $\alpha^{\prime}$-grain morphologies and textures, EBSD analysis was employed. Figure 7 shows the image quality (IQ), inverse pole figure (IPF), and pole figure maps of the SLM Ti64- $0 \%, 0.25 \%, 0.5 \%, 1 \%, 5 \%$, and $10 \% \mathrm{TiB}_{2}$ composites. In both the $0 \% \mathrm{TiB}_{2}$ - and $0.25 \% \mathrm{TiB}_{2}$-added samples, the prior $\beta$-grains with a strong columnar texture consisting of acicular $\alpha^{\prime}$ grains existed along the building direction and showed a higher maximum intensity $\left(I_{\max }\right)$ of 10.4-12.2 than those of the other samples $\left(I_{\max }=2.3-4.2\right)$. This means that a high B content causes randomized $\alpha^{\prime}$-grain textures. The prior $\beta$-grains of the SLM Ti64-0.5\% TiB ${ }_{2}$ composite (Figure 7c) formed parallel to the building direction and mainly consisted of acicular $\alpha^{\prime}$-grains, but some equiaxed grains were also observed. When the pre-mixed Ti64-1-10\% $\mathrm{TiB}_{2}$ powders were employed, only equiaxed $\alpha^{\prime}$-grains with weak crystal orientations formed in the prior $\beta$-grains of the SLM samples, as shown in Figure $7(\mathrm{~d}-\mathrm{f})$. The Ti64-10\% $\mathrm{TiB}_{2}$ composite (Figure $7 \mathrm{f}$ ) also contained acicular whiskers along the molten pool boundary, as shown in Figure 6.

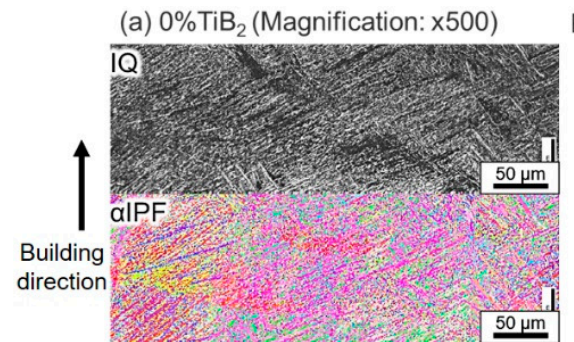

(b) $0.25 \% \mathrm{TiB}_{2}$ (Magnification: $\times 500$ )

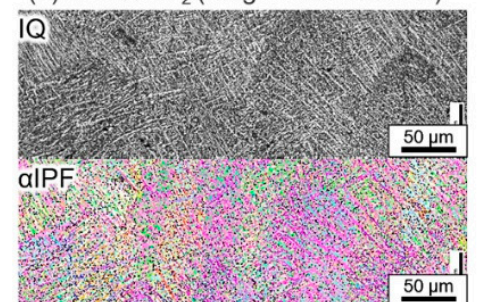

(c) $0.5 \% \mathrm{TiB}_{2}$ (Magnification: $\times 500$ )

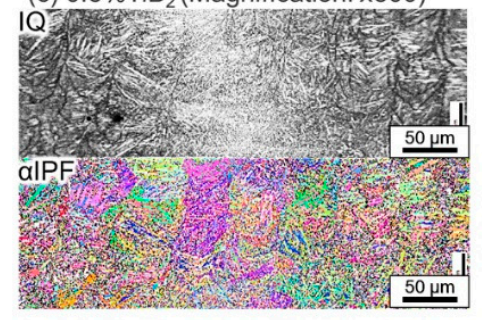

Polar Figure map
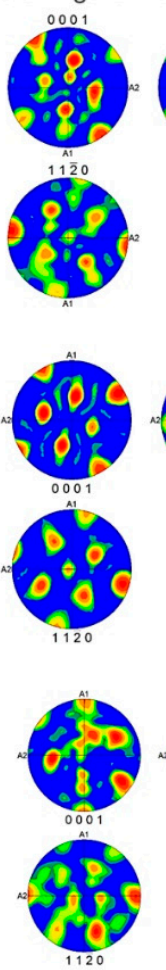
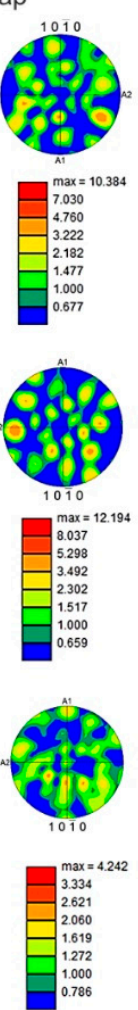

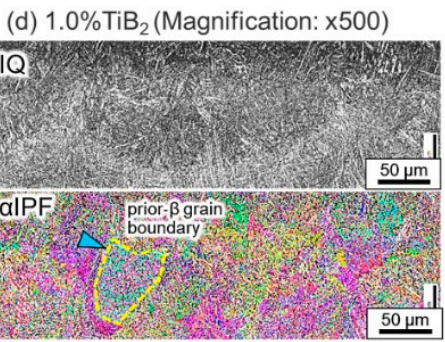

(e) $5 \% \mathrm{TiB}_{2}$ (Magnification: $\times 5000$ )

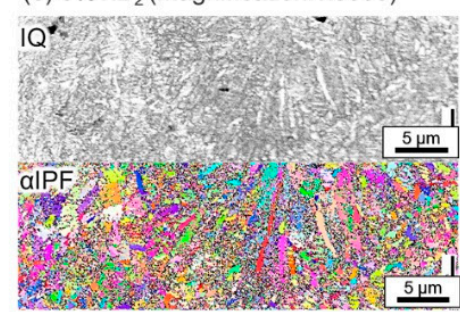

(f) $10 \% \mathrm{TiB}_{2}$ (Magnification: $\times 5000$ )

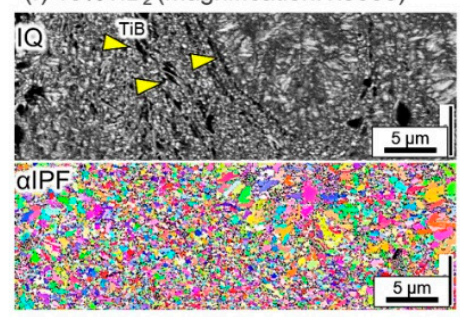

Polar Figure map
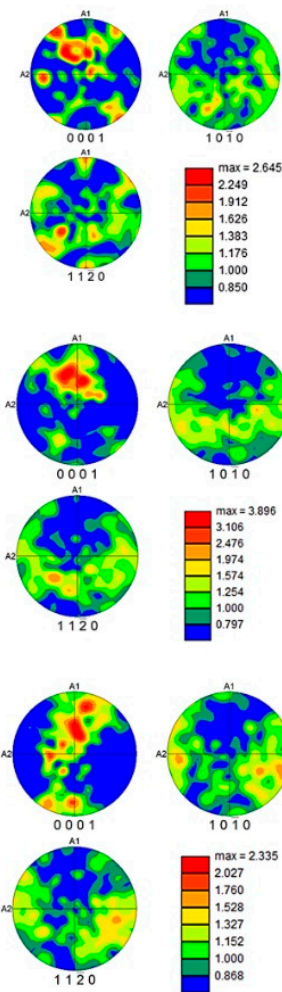

Figure 7. Image quality (IQ), inverse pole figure (IPF), and pole figure maps of $\alpha$-phase of SLM Ti64- (a) 0, (b) 0.25, (c) 0.5, (d) 1.0, (e) 5 , and (f) 10 mass\% $\mathrm{TiB}_{2}$ composites analyzed by SEM-EBSD. 
SEM-EBSD under a higher magnification was carried out to quantitatively evaluate the size factors (length, width, and aspect ratio) of the acicular $\alpha^{\prime}$-grains when a small amount of $\mathrm{TiB}_{2}$ particles $(0,0.25,0.5$, and 1 mass $\%)$ was added. Table 3 summarizes the measured factors ( 30 measurements for each sample), and Figure 8 shows the dependence of each size factor on the B content of the SLM Ti64- $\mathrm{TiB}_{2}$ composites. All factors gradually decreased with increasing B content; in particular, the $1.43 \mu \mathrm{m}$ length of the $1 \% \mathrm{TiB}_{2}$-added sample was significantly smaller than that of the monolithic Ti64 alloy, $4.58 \mu \mathrm{m}$. In other words, a notable decrease in the aspect ratio of the acicular $\alpha^{\prime}$-grains occurred with increasing $\mathrm{TiB}_{2}$ content. It is concluded that acicular $\alpha^{\prime}$-grain growth was effectively obstructed by the $B$ element, causing refinement of the prior equiaxed $\beta$-phases by the distributed TiBw. In addition, the primary $\alpha^{\prime}$-grains precipitated from the $\beta$-phases are effective in obstructing the coarsening behavior of secondary $\alpha^{\prime}$-grains.

Table 3. Changes in the length, width, and aspect ratio of acicular $\alpha^{\prime}$-grains in SLM Ti64 alloy composites with different $\mathrm{TiB}_{2}$ contents.

\begin{tabular}{|c|c|c|c|c|c|c|c|c|c|c|}
\hline \multirow{2}{*}{$\begin{array}{l}\mathrm{TiB}_{2} \text { Content } \\
\text { (mass } \% \text { ) }\end{array}$} & \multirow{2}{*}{$\begin{array}{l}\text { B Content } \\
\text { (mass } \%)\end{array}$} & \multicolumn{4}{|c|}{ Length/ $/ \mu \mathrm{m}$} & \multicolumn{4}{|c|}{ Width $/ \mu \mathrm{m}$} & \multirow{2}{*}{ Aspect Ratio } \\
\hline & & Mean & Max. & Min. & $\mathrm{SD}^{*}$ & Mean & Max. & Min. & $\mathrm{SD}^{*}$ & \\
\hline 0 & 0 & 4.58 & 38.15 & 0.56 & 4.14 & 0.73 & 4.22 & 0.16 & 0.47 & 4.74 \\
\hline 0.25 & 0.07 & 4.30 & 35.87 & 0.46 & 4.01 & 0.61 & 3.80 & 0.13 & 0.42 & 4.39 \\
\hline 0.5 & 0.15 & 1.67 & 18.17 & 0.46 & 1.53 & 0.47 & 2.14 & 0.12 & 0.24 & 4.24 \\
\hline 1.0 & 0.31 & 1.43 & 7.36 & 0.44 & 0.82 & 0.36 & 1.44 & 0.14 & 0.24 & 3.17 \\
\hline
\end{tabular}

* Standard deviation.

(a) $0 \% \mathrm{TiB}_{2}$ (Magnification: $\left.x 5000\right)$

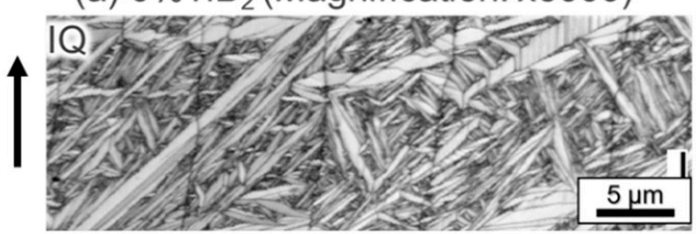

(b) $0.25 \% \mathrm{TiB}_{2}$ (Magnification: $\times 5000$ )

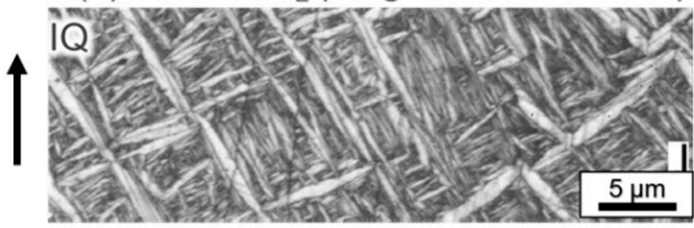

(c) $0.5 \% \mathrm{TiB}_{2}$ (Magnification: $x 5000$ )

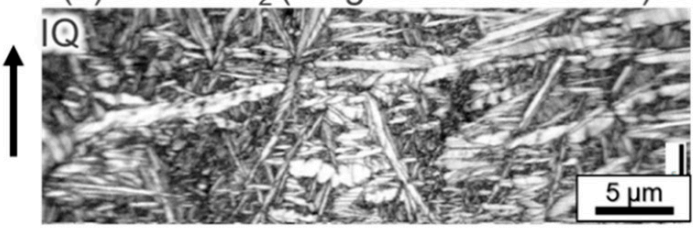

(d) $1.0 \% \mathrm{TiB}_{2}$ (Magnification: $\times 5000$ )

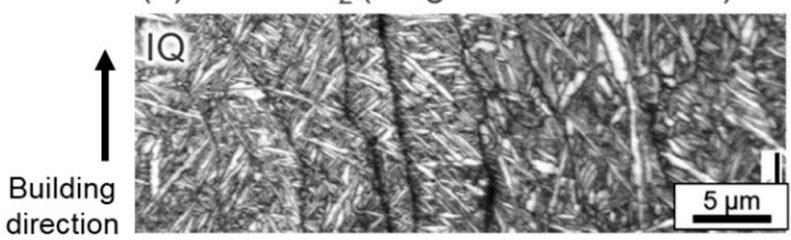

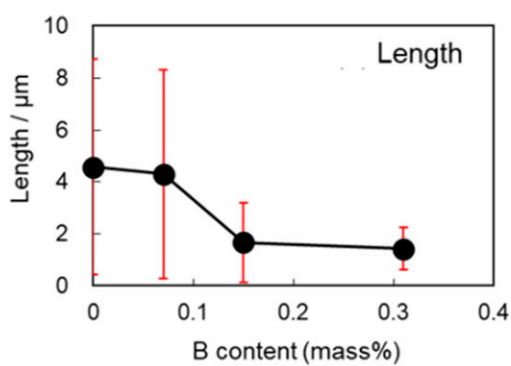
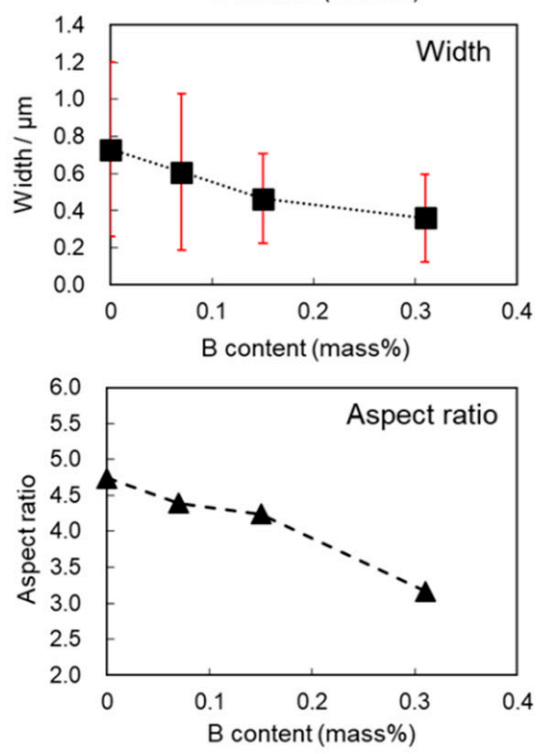

Figure 8. IQ maps of $\alpha$-phase of SLM Ti64- (a) 0 , (b) 0.25 , (c) 0.5 , and (d) 1.0 mass $\% \mathrm{TiB}_{2}$ composites and dependence of the length, width, and aspect ratio of the $\alpha^{\prime}$-phase on B content for each sample. 


\subsection{TiBw Distribution in Molten Pool Induced by Laser Irradiation}

The above microstructural investigation indicated that the in situ-formed TiBw distribution strongly depends on the B content of the SLM Ti64 alloys. However, it is well known that the microstructural formation of SLM metal materials is highly complicated because, in general, repeated laser irradiation is applied to the material during building, and thus the microstructure depends on the thermal history [17]. Importantly, the shape and morphology of the molten pool are also affected by repeated laser irradiation during the SLM process [18]. Accordingly, it is difficult to clarify the TiBw formation and distribution behaviors in SLM Ti64-TiB 2 composites. Therefore, microstructural analysis of molten pools of $\mathrm{Ti}_{64}-\mathrm{TiB}_{2}$ green compacts was carried out after a single laser irradiation in this study. The green compacts were fabricated by hot compaction using pre-mixed Ti64 alloy powders with $1 \%, 5 \%$, and $10 \% \mathrm{TiB}_{2}$ particles. The microstructural observations of the cross-section of each sample are shown in Figure 9. All samples showed a similar keyhole induced by the single laser irradiation, where the depth, width, and height of the molten pools were $665-708,350-440$, and $26-43 \mu \mathrm{m}$, respectively. These values indicate that there were no significant differences in the molten pool profiles for different contents of $\mathrm{TiB}_{2}$ particles.
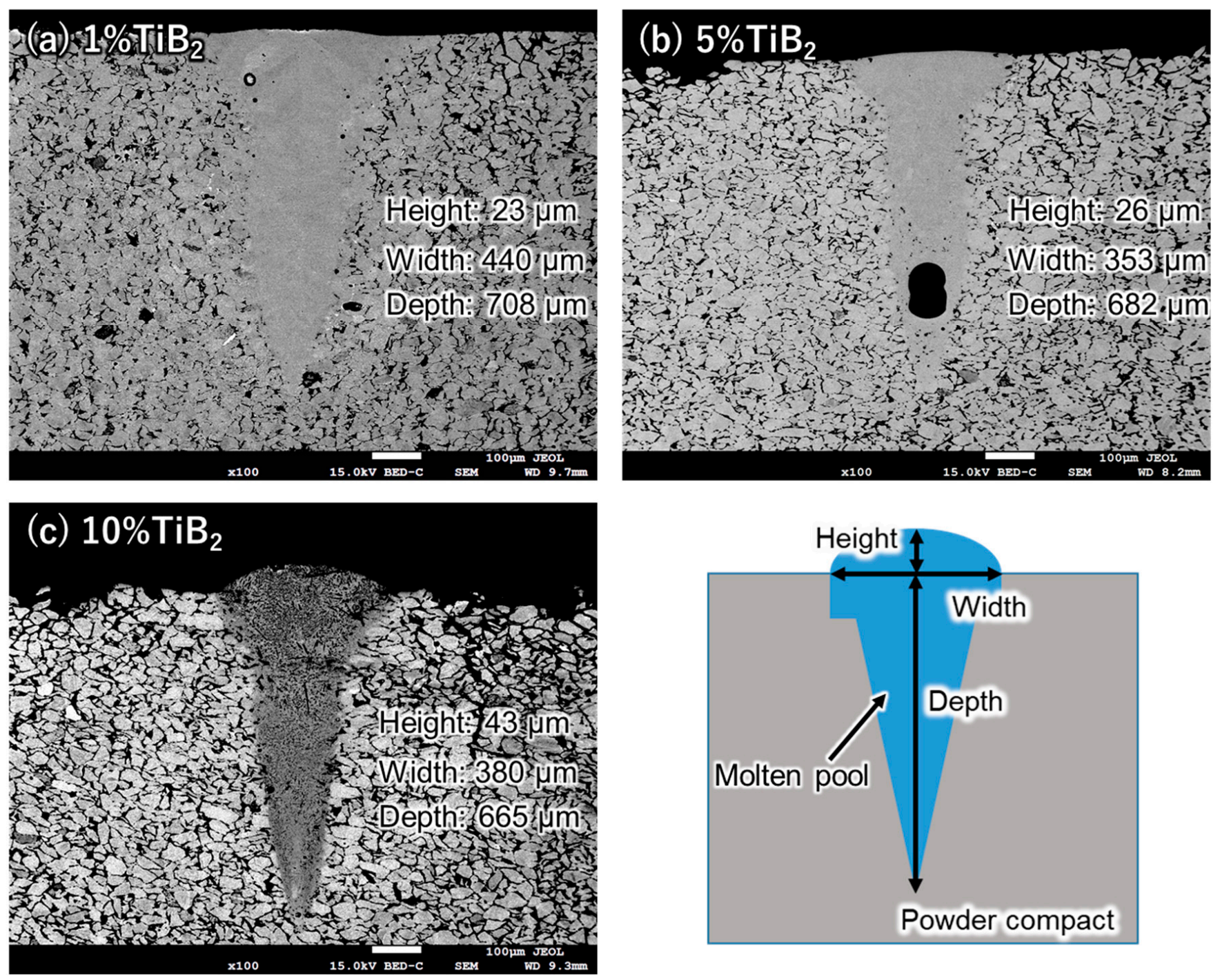

Figure 9. Cross-sectional COMPO images of molten pools induced by a single laser irradiation of Ti64- (a) 1, (b) 5, and (c) 10 mass $\% \mathrm{TiB}_{2}$ pre-mixed powder compacts. 
SEM analysis was performed to observe the microstructures at the center of the keyholes in the molten pools formed in the green compacts by a single laser irradiation. As shown in Figure 10, the Ti64- $1 \% \mathrm{TiB}_{2}$ and $\mathrm{Ti} 64-5 \% \mathrm{TiB}_{2}$ composites had similar microstructures, as shown in Figure $5 \mathrm{~b}, \mathrm{c}$, respectively. In particular, the $5 \% \mathrm{TiB}_{2}$-added sample contained equiaxed grains and small TiBw agglomerated at the prior $\beta$-grain boundaries. These results confirmed the reproducibility of the microstructural formation behavior, including in situ TiBw formation during the SLM process. In addition, repeated laser irradiation in SLM has no significant effect on the formation of equiaxed grains. On the other hand, the green compact of $\mathrm{Ti}^{2} 4-10 \% \mathrm{TiB}_{2}$ (Figure 10c) contained a distribution of remarkably large in situ-formed TiB whiskers (50-100 $\mu \mathrm{m}$ in length) compared with the SLM composites shown in Figure 6. This is due to the difference in solidification and cooling rates of the molten pool induced by repeated laser irradiation of the powders (SLM process) versus laser irradiation of the green compact. Furthermore, these TiB whiskers randomly grew inside the molten pool and never agglomerated at the boundaries. This is quite different from the microstructure of the SLM Ti64-10\% $\mathrm{TiB}_{2}$ composite with many in situ-formed TiBw at the molten pool boundaries, as shown in Figures 4c and 6. This is because Marangoni convection $[19,20]$ in the molten pool caused by repeated laser irradiation enhances the movement of the whiskers to the molten pool boundaries between the liquid and solid phases.
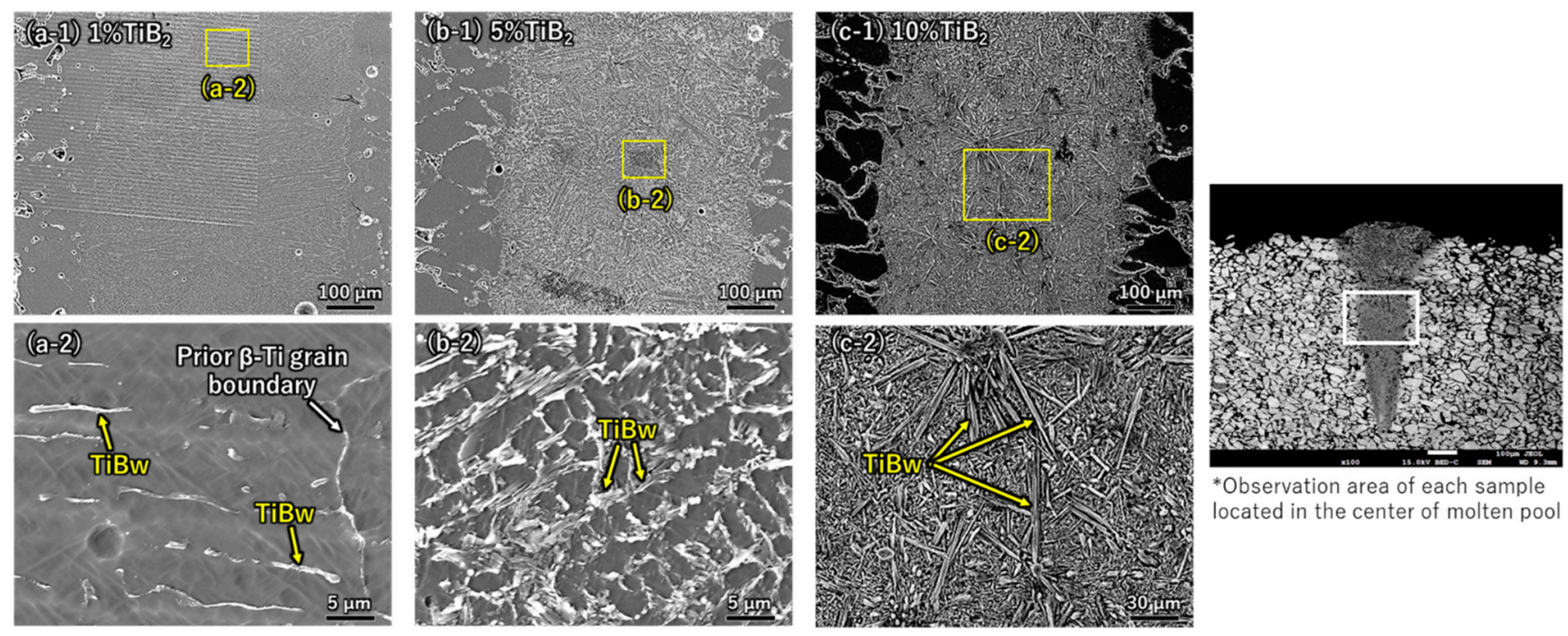
ocated in the center of molten pool

Figure 10. SEM images of the center of the molten pools on Ti64- (a) 1, (b) 5, and (c) 10 mass\% $\mathrm{TiB}_{2}$ pre-mixed powder compacts ((-1) low magnification and (-2) high magnification).

\subsection{TiBw Distribution Mechanism of SLM Ti64-TiB 2 Composites}

According to the results of the above investigation, it is clear that the microstructure of SLM Ti64- $\mathrm{TiB}_{2}$ composites, particularly the TiBw distribution, strongly depends on the B content because the $\mathrm{TiB}$ precipitation behavior is different between Groups I and II, as shown in the Ti64-B phase diagram (Figure 3). Figure 11 schematically illustrates the microstructural formation mechanism of SLM Ti64-TiB ${ }_{2}$ composites during the liquid $\rightarrow \beta$-phase transformation. In the monolithic Ti64 alloy with no $\mathrm{TiB}_{2}$ particles, the $\beta$-phase generally grows epitaxially in the building direction starting from the solid-liquid interface. This was observed by SEM, which showed $\beta$-phase growth from the molten pool boundary to the center of the pool. In Group I with $\mathrm{B}<2 \mathrm{mass} \%\left(1 \%\right.$ and $5 \% \mathrm{TiB}_{2}$ particle addition), as shown in Figure 11b, as the epitaxial growth of the $\beta$-phase starts from the interface during the liquid $\rightarrow \beta$ phase transformation, $\mathrm{B}$ atoms are discharged from the $\beta$-phase because of the low solubility (0.02 mass $\%)$ of $B$ in the $\beta$-Ti phase. The resulting $B$-enriched region around the $\beta$-phase decreases the liquidus temperature, which results in 
coarsening and obstruction of $\beta$-phase growth. The effect of $B$ enrichment was especially strong in the $5 \% \mathrm{TiB}_{2}$-added sample, resulting in the formation and refinement of equiaxed prior $\beta$-grains, as shown in Figure 5(c-1). Upon reaching the solidus temperature, TiB precipitation occurs in the B-enriched region, causing the agglomeration of TiBw at the prior $\beta$-grain boundaries, as observed in the SEM analysis. Some TiB whiskers were present along the building direction inside the prior $\beta$-grains, as shown in Figure $5(b-1)$, because the whiskers grow in the direction of the larger thermal gradient during cooling [3,21]. Furthermore, the uniform distribution of in situ-formed TiBw obstructs the growth and coarsening behavior of the acicular $\alpha^{\prime}$-phase even with only a small amount of added $\mathrm{TiB}_{2}$ particles (0.25-0.5 mass \%). As a result, the length and aspect ratio of the acicular $\alpha^{\prime}$-phase gradually decreased, as shown in Figure 8, and orientation randomization occurred, with a lower maximum intensity $\left(I_{\max }\right.$, Figure 7) at higher B contents in the SLM Ti64 composites.

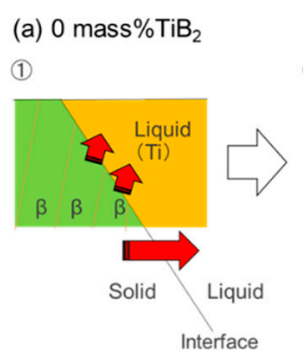

(b) $1 \% \& 5 \% \mathrm{TiB}_{2}$ (Group I)
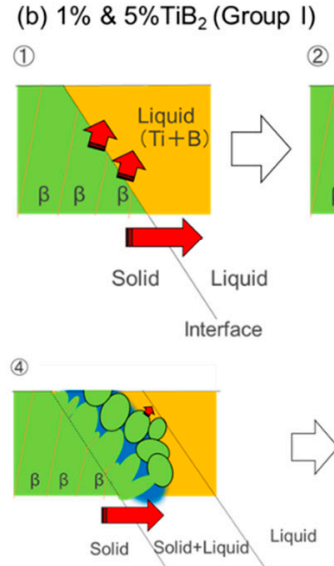

(2)

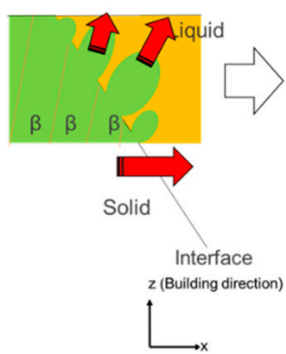

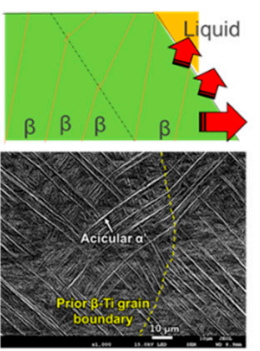

(c) $10 \% \mathrm{TiB}_{2}$ (Group II)

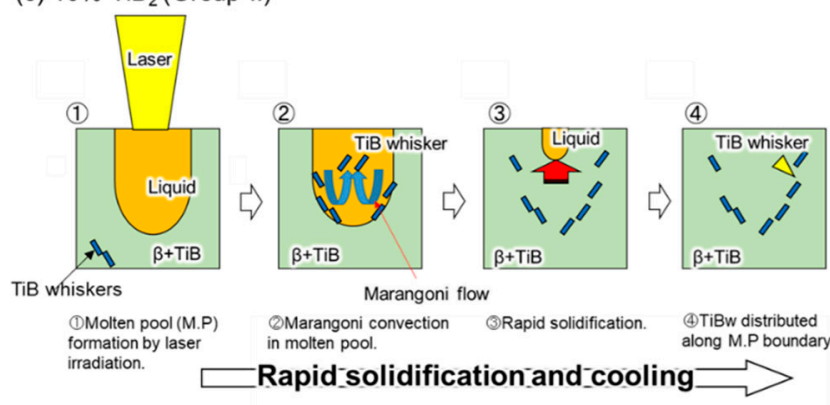

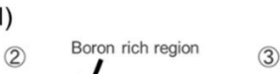

z (Building direction)

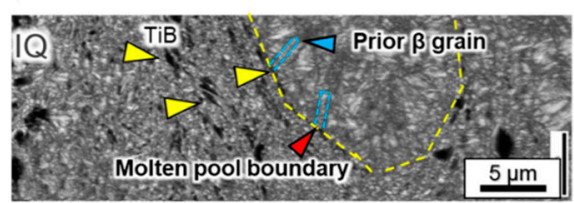

Figure 11. Schematic illustration of TiBw precipitation and distribution behaviors during the liquid $\rightarrow \beta$ phase transformation of Ti64- (a) 0, (b) 1 \& 5 (Group I), and (c) 10 mass\% TiB 2 (Group II) with IQ maps.

In Group II (B > 2 mass\%, Ti64-10\% $\mathrm{TiB}_{2}$ composite), as shown in Figure 11c, the primary $\mathrm{TiB}$ whiskers precipitate inside the molten pool during cooling after laser irradiation. Marangoni convection caused by the large temperature difference in the liquid-phase molten pool enhances the movement of TiBw to the molten pool boundary. As a result, the whiskers agglomerated at the boundaries, as shown in Figures $4 \mathrm{c}$ and 6 . Regarding the microstructural formation behavior of the matrix, $\beta$-grain precipitation starts from those TiBw acting as nucleation sites during solidification, and their grains grow toward the center of the molten pool in the higher-temperature region according to the temperature gradient.

\section{Conclusions}

It was clarified that the distribution behavior of $\mathrm{TiB}$ whiskers formed in situ from $\mathrm{TiB}_{2}$ particles in SLM Ti64 composites strongly depends on their primary precipitation from the liquid phase controlled by the B content. For B contents of less than 2 mass $\%$ (Group I, $1 \%$ and $5 \% \mathrm{TiB}_{2}$ ), when the liquid $\rightarrow \beta$ phase transformation occurred, $\mathrm{B}$ atoms 
were discharged and a B-enriched region formed around the $\beta$-phase. As a result, TiB whiskers were generated based on this B-enriched area and agglomerated at the prior $\beta$-grain boundaries. The in situ-formed TiBw in the prior $\beta$-grains then dissolved during cooling, resulting in a solid solution of B elements in the $\beta$-phase. Finally, acicular TiB whiskers precipitated in the prior $\beta$-grains during cooling. On the other hand, when the $B$ content was over 2 mass \% (Group II, 10\% $\mathrm{TiB}_{2}$ ), TiB whiskers precipitated from the liquid phase and moved to the molten pool boundary by Marangoni convection, and thus the whiskers were present along the boundaries. Furthermore, the B-enriched region around $\beta$-grains decreased the liquidus temperature, which both obstructed $\beta$-grain coarsening and caused $\alpha^{\prime}$-grain refinement during the phase transformation.

Author Contributions: J.U.: Conceptualization, Investigation, Writing-original draft, Writingreview \& editing, Visualization. L.J.: Methodology, Investigation. B.C.: Investigation, Visualization. K.C.: Resources, Supervision. S.L.: Resources, Supervision. K.S.: Formal analysis, Visualization. K.K.: Methodology, Supervision, Funding acquisition. All authors have read and agreed to the published version of the manuscript.

Funding: This research was funded by the Council for Science, Technology and Innovation (CSTI), Cross-Ministerial Strategic Innovation Promotion Program (SIP), “Materials integration for revolutionary design system of structural materials" (Funding agency: JST), International Joint Research Promotion Program promoted by Osaka University, the Amada Foundation under Research \& Development Grant (AF-2018215), and the Light Metal Educational Foundation.

Institutional Review Board Statement: Not applicable.

Informed Consent Statement: Not applicable.

Data Availability Statement: The data presented in this study are available on request from the corresponding author.

Acknowledgments: This study was financially supported by the Council for Science, Technology and Innovation (CSTI), Cross-Ministerial Strategic Innovation Promotion Program (SIP), "Materials integration for revolutionary design system of structural materials" (Funding agency: JST), International Joint Research Promotion Program promoted by Osaka University, the Amada Foundation under Research \& Development Grant (AF-2018215), and the Light Metal Educational Foundation. The authors also thank K. Kamiyama for conducting the experiments.

Conflicts of Interest: The authors declare no conflict of interest.

\section{References}

1. Jia, L.; Li, X.; Kondoh, K.; Chen, B.; Li, S.; Umeda, J.; Lu, Z. Hybrid Effect of TiCp and TiBw Co-Strengthening Ti Matrix Composites Prepared by Spark Plasma Sintering and Hot Extrusion. Mater. Charact. 2019, 151, 6-14. [CrossRef]

2. Kurita, H.; Suzuki, S.; Kikuchi, S.; Yodoshi, N.; Gourdet, S.; Narita, F. Strengthening Mechanism of Titanium-Boride WhiskerReinforced Ti-6Al-4V Alloy Matrix Composites with the TiB Orientation Perpendicular to the Loading Direction. Materials 2019, 12, 2401. [CrossRef] [PubMed]

3. Xue, A.; Lin, X.; Wang, L.; Wang, J.; Huang, W. Influence of Trace Boron Addition on Microstructure, Tensile Properties and Their Anisotropy of Ti6Al4V Fabricated by Laser Directed Energy Deposition. Mater. Des. 2019, 181, 107943. [CrossRef]

4. Ding, L.; Nakasa, K.; Kato, M.; Tachiyama, T. Fabrication of TiB-TiC, TiB-TiN and TiB 2 -TiC Composites and Their Bonding to Ti-6Al-4V Alloy by Spark and Resistance Sintering; The Japan Institute of Metals: Sendai, Japan, 2002; Volume 66, pp. 597-605.

5. Mceldowney, D.J.; Tamirisakandala, S.; Miracle, D.B. Heat-Treatment Effects on the Microstructure and Tensile Properties of Powder Metallurgy Ti-6Al-4V Alloys Modified with Boron. Metall. Mater. Trans. A 2010, 41, 1003-1015. [CrossRef]

6. Schmidt, J.; Boehling, M.; Burkhardt, U.; Grin, Y. Preparation of Titanium Diboride TiB 2 by Spark Plasma Sintering at Slow Heating Rate. Sci. Technol. Adv. Mater. 2007, 8, 376-382. [CrossRef]

7. Ma, F.; Liu, P.; Li, W.; Liu, X.; Chen, X.; Zhang, K.; Pan, D.; Lu, W. The Mechanical Behavior Dependence on the TiB Whisker Realignment during Hot-Working in Titanium Matrix Composites. Sci. Rep. 2016, 6, 36126. [CrossRef] [PubMed]

8. Li, S.; Kondoh, K.; Imai, H.; Chen, B.; Jia, L.; Umeda, J.; Fu, Y. Strengthening Behavior of In Situ-Synthesized (TiC-TiB)/Ti Composites by Powder Metallurgy and Hot Extrusion. Mater. Des. 2016, 95, 127-132. [CrossRef]

9. Li, S.; Kondoh, K.; Imai, H.; Chen, B.; Jia, L.; Umeda, J. Microstructure and Mechanical Properties of P/M Titanium Matrix Composites Reinforced by In-Situ Synthesized TiC-TiB. Mater. Sci. Eng. A 2015, 628, 75-83. [CrossRef]

10. Huang, L.J.; Geng, L.; Wang, B.; Xu, H.Y.; Kaveendran, B. Effects of Extrusion and Heat Treatment on the Microstructure and Tensile Properties of In Situ TiBw/Ti6Al4V Composite with a Network Architecture. Compos. A 2012, 43, 486-491. [CrossRef] 
11. Issariyapat, A.; Visuttipitukul, P.; Umeda, J.; Kondoh, K. Refined Grain Formation Behavior and Strengthening Mechanism of $\alpha$-Titanium with Nitrogen Fabricated by Selective Laser Melting. Addit. Manuf. 2020, 36, 101537. [CrossRef]

12. Kondoh, K.; Ichikawa, E.; Issariyapat, A.; Shitara, K.; Umeda, J.; Chen, B.; Li, S. Tensile Property Enhancement by Oxygen Solutes

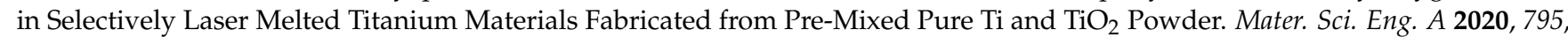
139983. [CrossRef]

13. Zhang, D.; Prasad, A.; Bermingham, M.J.; Todaro, C.J.; Benoit, M.J.; Patel, M.N.; Qiu, D.; Stjohn, D.H.; Qian, M.; Easton, M.A. Grain Refinement of Alloys in Fusion-Based Additive Manufacturing Processes. Metall. Mater. Trans. A 2020, 51, 4341-4359. [CrossRef]

14. Pan, D.; Zhang, X.; Hou, X.; Han, Y.; Chu, M.; Chen, B.; Jia, L.; Kondoh, K.; Li, S. TiB Nano-Whiskers Reinforced Titanium Matrix Composites with Novel Nano-Reticulated Microstructure and High Performance via Composite Powder by Selective Laser Melting. Mater. Sci. Eng. A 2021, 799, 140137. [CrossRef]

15. Lia, H.; Jiaa, D.; Yanga, Z.; Zhoua, Y. Achieving near Equiaxed $\alpha$-Ti Grains and Significantly Improved Plasticity via Heat Treatment of TiB Reinforced Titanium Matrix Composite Manufactured by Selective Laser Melting. J. Alloys Compd. 2020, 836, 155344. [CrossRef]

16. Zhang, L.C.; Attar, H. Selective Laser Melting of Titanium Alloys and Titanium Matrix Composites for Biomedical Applications: A Review, Material technology. Adv. Perform. Mater. 2016, 31, 66-76.

17. Yang, J.; Yu, H.; Yin, J.; Gao, M.; Wang, Z.; Zeng, X. Formation and Control of Martensite in Ti-6Al-4V Alloy Produced by Selective Laser Melting. Mater. Des. 2016, 108, 308-318. [CrossRef]

18. Shifeng, W.; Shuai, L.; Qingsong, W.; Yan, C.; Sheng, Z.; Yusheng, S. Effect of Molten Pool Boundaries on the Mechanical Properties of Selective Laser Melting Parts. J. Mater. Process. Technol. 2014, 214, 2660-2667. [CrossRef]

19. Höche, D.; Müller, S.; Rapin, G.; Shinn, M.; Remdt, E.; Gubisch, M.; Schaaf, P. Marangoni Convection During Free Electron Laser Nitriding of Titanium. Metall. Mater. Trans. B 2009, 40, 497-507. [CrossRef]

20. Gugliotti, M.; Baptista, M.S.; Politi, M.J. Laser-Induced Marangoni Convection in the Presence of Surfactant Monolayers. Langmuir 2002, 18, 9792-9798. [CrossRef]

21. Bermingham, M.J.; Mcdonald, S.D.; Dargusch, M.S. Effect of Trace Lanthanum Hexaboride and Boron Additions on Microstructure, Tensile Properties and Anisotropy of Ti-6Al-4V Produced by Additive Manufacturing. Mater. Sci. Eng. A 2018, 719, 1-11. [CrossRef] 